University of Montana

ScholarWorks at University of Montana

Graduate Student Theses, Dissertations, \&

Professional Papers

2001

\title{
Effects of liquid carbohydrate feeding on salivary IgA during exercise in a heated environment
}

Kent C. Hansen

The University of Montana

Follow this and additional works at: https://scholarworks.umt.edu/etd

Let us know how access to this document benefits you.

\section{Recommended Citation}

Hansen, Kent C., "Effects of liquid carbohydrate feeding on salivary IgA during exercise in a heated environment" (2001). Graduate Student Theses, Dissertations, \& Professional Papers. 6233.

https://scholarworks.umt.edu/etd/6233

This Thesis is brought to you for free and open access by the Graduate School at ScholarWorks at University of Montana. It has been accepted for inclusion in Graduate Student Theses, Dissertations, \& Professional Papers by an authorized administrator of ScholarWorks at University of Montana. For more information, please contact

scholarworks@mso.umt.edu. 


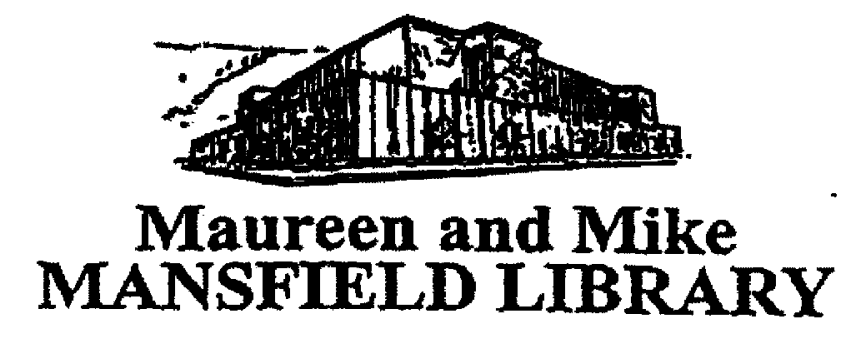

The University of

Montana

Permission is granted by the author to reproduce this material in its entirety, provided that this material is used for scholarly purposes and is properly cited in published works and reports.

**Please check "Yes" or "No" and provide signature**

Yes, I grant permission

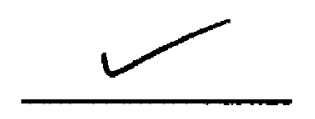

No, I do not grant permission

Author's Signature:

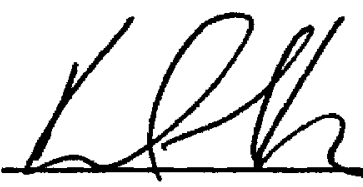

Date: $11 / 24 / 01$

Any copying for commercial purposes or financial gain may be undertaken only with the author's explicit consent. 
Effects of Liquid Carbohydrate Feeding on Salivary IgA During Exercise in a Heated Environment

Director: Dr. Brent Ruby 62

\section{ABSTRACT}

PURPOSE: The purpose of this study is to quantify the effects of prolonged exercise and carbohydrate ( $\mathrm{CHO}$ ) feedings in a heated environment on the salivary immune marker IgA. METHODS: In a randomized double-blind design, 11 recreationally active males and females walked for $120 \mathrm{~min}$ at ventilatory threshold (VT) in the heat $\left(39^{\circ} \mathrm{C}\right)$ on two occasions while fed $\mathrm{CHO}$ or sweet placebo ( $\mathrm{Pla}$ ). Females performed both heat trials within 7 days post-menses to minimize hormonal variations in metabolism. $\mathrm{CHO}$ was delivered in a $7 \%$ solution and based on fat-free mass, $1.16 \mathrm{~g} \mathrm{~kg} \mathrm{FFM}^{-1} 60 \mathrm{~min}^{-1}\left(0.7 \mathrm{~g} \mathrm{~kg}\right.$ body mass $^{-}$ $\left.{ }^{1} .60 \mathrm{~min}^{-1}\right)$. Blood samples were collected at baseline, at 30 min intervals during exercise, and immediately post-exercise. Timed saliva samples were collected at baseline, post-exercise, and 1 and $6 \mathrm{hrs}$ post-exercise. RESULTS: VT resulted in a highly homogenous physiological response $(P=0.70)$. Plasma glucose levels became significant only at $120 \mathrm{~min}$ of exercise $(P<0.01)$. Saliva flow rate had no significant variations. Salivary $\lg A$ (s-lgA) concentration and sIga secretion rate had significant declines when compared to rest in the $\mathrm{CHO}$ and Pla trials $(P<0.035)$, however, there were no significant variations across trials. CONCLUSION: These findings suggest that heat exacerbates the effect exercise has on s-IgA parameters and hot ambient temperatures delay any benefit $\mathrm{CHO}$ supplementation may have on attenuating a diminished immune system in moderate temperatures. This project was funded through a grant provided by the Missoula Technical and Development Center. 
By

Kent C. Hansen

B.A. Concordia College, Moorhead, MN, 1991

presented in partial fulfillment of the requirements

for the degree of

Master of Science

The University of Montana

November, 2001

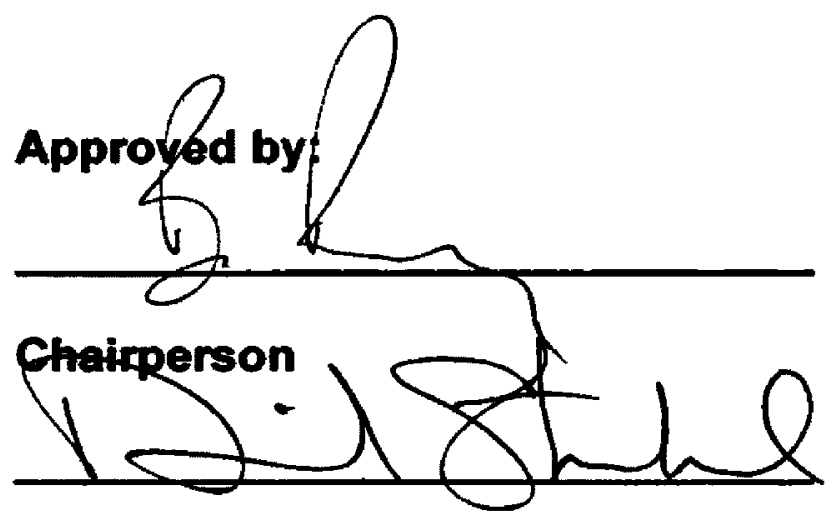

\section{Dean Graduate School}

$|2-10-0|$

Date: 


\section{All rights reserved}

\section{INFORMATION TO ALL USERS}

The quality of this reproduction is dependent upon the quality of the copy submitted.

In the unlikely event that the author did not send a complete manuscript and there are missing pages, these will be noted. Also, if material had to be removed, a note will indicate the deletion.

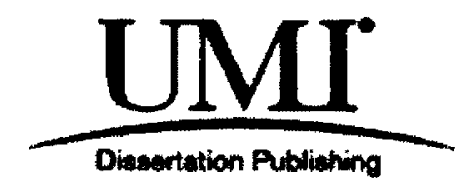

UMI EP37034

Published by ProQuest LLC (2013). Copyright in the Dissertation held by the Author. Microform Edition ( ) ProQuest LLC.

All rights reserved. This work is protected against unauthorized copying under Title 17, United States Code

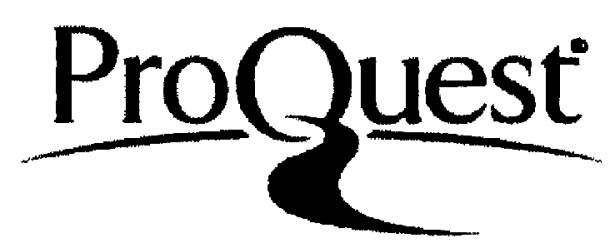

ProQuest LLC.

789 East Eisenhower Parkway

P.O. Box 1346

Ann Arbor, MI $48106-1346$ 


\section{Table of Contents}

Chapter One

Chapter Two

Chapter Three

Chapter Four

Chapter Five

Introduction

Review of Literature

9

Methodology

10

Results

15

Discussion

18

References

24

Figure Legend

39 


\section{List of Tables}

Table One

Table Two

Table Three

Table Four

Table Five

Figure One

Figure Two

Figure Three

Figure Four

Figure Five

Figure Six
Physical Characteristics

Actual Workload

HR, CT, and RPE

Changes in Lactate and Glycerol

Changes in Blood Immune Markers

Changes in Plasma Glucose

Changes in Salivary Flow Rate

Changes in slgA concentration

Changes in IgA secretion rate

Changes in Protein secretion rate

Changes in IgA relative to Protein

38 


\section{Chapter One: Introduction}

\section{Introduction}

There is substantial anecdotal information from athletes, trainers and coaches, suggesting that rigorous physical activity increases the risk of upper respiratory tract infection (URTI) ${ }^{24,45.48}$. The Wildland Firefighter, to some, an unorthodox endurance athlete, becomes a unique example of this paradigm with similar physiological battles.

Wildland firefighting demands a high energy output averaging $7.5 \mathrm{kcal}$ per minute, over $400 \mathrm{kcal}$ per hour, and up to $6000 \mathrm{kcal}$ per day ${ }^{51}$. Rigorous activity and heavy exertion (physiological stress) increases circulating epinephrine and cortisol, which may suggest alterations to the normal immune response ${ }^{40,46}$. Coupling this highenergy work with psychological stress, the physical environment, long hours and multiple consecutive shifts, little sleep, the difficulty in maintaining energy and/or hydration balance achieves a dangerous scenario, which may result in acute and/or chronic overtraining and immunosuppression.

The immune system is comprised of an intricate system of organs, tissues, cells and molecules, which try to maintain homeostasis within all living beings. All forms of stress from psychological to physical influence this attempt at homeostasis. Once a pathogen has accessed the body the integrated immune response is initiated. This study is most interested in the mucosal immune system and with the increased risk for upper respiratory tract infections.

The mucosal immune system is a network of immune structures at mucosal surfaces throughout the body that provides effective protection at distal sites from the original site of antigen presentation ${ }^{5}$. The mucosal immune system is systemic involving many aspects of the body, however, the focus of this investigation includes the respiratory tract and the salivary $\lg A$ marker. 
Effective immunity in the URTI challenge begins at the mucosal surfaces with sIgA playing a major role in defense of homeostasis. This specific response in association with a general immune response is required to maintain an asymptomatic state to URTI's. A state of immunosuppression weakens this system and it is suggested that levels of s-IgA may influence the risk for URTI ${ }^{20,31,35,54}$.

The immune system is a high-energy system when battling pathogens. Most immune responses involve cell replication and the production of proteins with specific functions. The mechanisms by which nutrient deficiencies affect the immune system have been classified as either direct or indirect. A nutritional deficiency is said to have a direct effect when the nutritional factor being considered has primary activity within the lymphoid system and an indirect effect when the primary activity affects all cellular material, or another organ system, which acts as an immune regulator ${ }^{10}$. For example, carbohydrate availability directly affects a number of leukocyte functions but also exerts an indirect effect on the lymphoid system through its influence on circulating levels of the catecholamines, adrenocorticotrophic hormone and cortisol ${ }^{17}$ during exercise. In addition, carbohydrate supplementation modifies the immune response imposed by exercise ${ }^{18,25}$. In what way does it "modify" the immune response

Wildland firefighters attempt homeostasis despite numerous stresses including physical and psychological which have all been shown to depress the immune system including the specific marker, s- $\lg A 11,20,31,35,54$. One of the many stressors affecting the battle for homeostatic maintenance for Wildland Firefighters is heat. These athletes are working in the hottest days of the year and fully dressed in fire protective clothing while maintaining a high level of energy output suppressing fires, up to $6000 \mathrm{kcals} / \mathrm{day}{ }^{51}$ in harsh environments.

Ambient temperatures exceeding body temperature stress thermoregulatory systems in the body to release excess heat, which is only exacerbated with exercise. 
Housh et al. ${ }^{26}$ showed that acute exposure to various temperatures, up to $34^{\circ} \mathrm{C}$, have no effect on s-IgA levels. Wildland Firefighters are exposed to high ambient temperatures exceeding $34^{\circ} \mathrm{C}$ for extended periods of time. Performance, measured as either time to exhaustion or work output during a specific task, is reduced in the heat ${ }^{12,14}$ and proportional to the increase in core temperature.

Adequate carbohydrate intake is an essential component to heavy training schedules, with a current recommended intake of 8-10g of carbohydrate per $\mathrm{kg}$ body mass for athletes training more than 2 hours per day ${ }^{23}$. The primary concerns addressed with such recommendations are restoration of muscle and liver glycogen. Additionally, glucose becomes important to cells of the immune system as an immediate source of energy in the battle against pathogens, thus, adding to the importance of adequate energy balance and carbohydrate intake.

If carbohydrate supplementation attenuates immunosuppressive episodes (decreased $s-\operatorname{lgA}$ ) then emphasizing proper carbohydrate intake and energy balance may help protect the Wildland Firefighter: from acute and/or chronic overtraining leading to immunosuppression and ultimately an URTI.

\section{Purpose}

The purpose of this study was to determine the effects of prolonged exercise in a heated environment on changes in salivary $\operatorname{lgA}$. This study examined and compared levels of sIgA and other general immune markers during exercise in the heat with two hydration/feeding regimens (carbohydrate and Pla).

\section{Research Hypothesis}

\section{Hypothesis One}

Carbohydrate feedings will attenuate a decrease in immune markers (s-lgA and CBC's) after prolonged exercise in a heated environment. 
Hypothesis Two

Plasma glucose and lactate will be elevated during the carbohydrate trial. Justification

Collectively, the literature suggests a depressed immune function after rigorous physical activity, which has a cumulative effect. Many studies have found depressed immune markers, s-lgA $20,31,35,54$, and suggest this as the cause for the prevalence of URTI's in endurance athletes. However, only one study has (Housh et al., 1991) looked at the effects of heat and exercise on s-lgA and no study has determined the result of prolonged exercise in a heated environment on the immune system, specifically s-lgA.

\section{Significance of Study}

In immunology and exercise studies, there has been only one published study ${ }^{26}$ that has used temperature to examine s-IgA levels after exercise. This study will be the first to investigate the effects of excessive heat and prolonged exercise on the immune system.

Most previous immunology and exercise studies have selected arbitrary set percentages of $\mathrm{VO}_{2 \max }$. There is an evolving argument centered upon relative, ventilatory and lactate thresholds, and absolute, $\mathrm{VO}_{2 \max }$, intensities. Relative intensities are derived from metabolic responses of an individual's physiology, which are a direct reflection of fitness level. Whereas absolute intensities account for the maximum volume of oxygen an individual may transport in a given short-term effort, which in large part is genetic (i.e. lung volume). Lung volume is much less variable due to fitness level than is the accumulation of lactate in the blood. Among the many physiological responses, ventilatory threshold is an indirect response to the accumulation of lactate in the blood.

Varying lactate thresholds may have significant effects on exercise metabolism, even in participants with a similar $\mathrm{VO}_{2 \max }{ }^{?}$. An illustration of this would be if two 
participants had the same $\mathrm{VO}_{2 \max }$ but different lactate thresholds, $55 \%$ and $75 \%$ of their $\mathrm{VO}_{2 \max }$. If the protocol calls for an intensity of $65 \%$ of $\mathrm{VO}_{2 \max }$, one participant would be exercising at a higher intensity than the other with a heavier reliance on carbohydrate. Ultimately, this is a great difference when a study's results are looking at comparative factors and metabolic influences.

In a repeated measures design the reduction of within group variability is vital in order to obtain a more homogenous response to variables introduced. Reduced variability between participants improves the power of detecting differences. The use of relative intensities to control for exercise intensity is used to address these methodological concerns of metabolic response studies.

\section{Rationale for the Study}

The investigation of heat and carbohydrate supplementation on the immune marker, s-lgA, is necessary to more fully understand immunosuppressive episodes due to acute bouts of work. Understanding how a replication of the stressors challenging the Wildland Firefighter may give additional insight into nutritional and/or hydration issues in order to maintain proper health over the course of a fire season.

\section{Limitations}

i/ Instrumentation. Inherent error is associated with all instrumentation. However, using trained testers, calibrated equipment and accounting for potential drift will minimize error. ii/ Non-randomized sample. The sample will not be randomly selected. Random selection is used to equalize compared groups on extraneous variables. This repeated measures design will use the same participants for both trials (carbohydrate vs. Pla) therefore eliminating confounding variables (e.g. immunity levels, fitness levels, psychological thresholds, training).

iii/ Hydration and nutritional status. Hydration occurred at regular intervals and was not limited. Nutrition, carbohydrate supplementation, was given at regular intervals during 
the carbohydrate trial. Depending on the circumstances, both hydration and nutrition is more limited for the Wildland Firefighter. Many times they are limited to what they carry in their backpack.

iv/ Stress level. Replication of actual environmental and psychological stressors of the Wildland Firefighter in the field are attempted and unfortunately minimized due to the fact that they cannot be duplicated.

v/ Isolated exercise task. Work of the Wildland Firefighter encompasses whole body movements and exercise. This study's exercise task will only replicate one aspect of their working environment, walking/hiking, in attempt to provide sufficient physiological stress.

vi/ Duration. The length of exercise, although prolonged for an exercise study, is quite short in the reality of Wildland Firefighter work.

vii/ Load carriage. Participants will carry no extraneous load beyond their own body weight. The Wildland Firefighter always carries a pack, which varies in weight.

\section{Delimitations}

i/ Participant type. The results of this study may have implications for Wildland Firefighters, therefore, minimum fitness qualifications as posed on the Wildland Firefighters are required for the study participants. These include a recreationally active lifestyle and a minimum of $50 \mathrm{ml} / \mathrm{kgFFM}^{-1} \cdot \mathrm{min}^{-1}$.

ii/ Hormonal limitations. Hormones influence metabolism, therefore, female participants had an additional qualification of no external hormonal influence, which predominantly is obtained through exogenous birth control measures. This investigation will also only accept eumenorrheic females, since hormonal influence is critical to metabolism, helping in the determination of early follicular presentation. Additionally, the female participants will be tested in the early follicular phase to capture their hormone cycle (progesterone and estrogen) at their least influential point. 
iii/ Environment. The actual working environment of the Wildland Firefighter is highly variable, whereas, the study will maintain a controlled environment $\left(39^{\circ} \mathrm{C}\right)$.

iv/ Intensity. This investigation will attempt to sufficiently stress the participants, as would a portion of the Wildland Firefighters typical workload.

v/ Hydration and nutritional status. Water was readily available and not limited. During the carbohydrate trial, a carbohydrate solution was provided regularly and uniformly based on each participant's fat free mass.

\section{Definition of Terms}

Early Follicular Phase. Days 1-7 immediately after menses stops during the female hormonal milieu.

Ventilatory Threshold. An intensity of exercise at which metabolic gases are affected and determined in the following ways:

ventilatory equivalents. The first rise in the ventilatory equivalent of oxygen without a concurrent rise in the ventilatory equivalents of carbon dioxide.

excess $\mathrm{CO}_{2}$ production. An increase from steady state to an excess production of $\mathrm{CO}_{2}$.

modified V-slope method. Plots the minute production of carbon dioxide over the minute utilization of oxygen.

Hydrostatic weighing. Determination of fat-free mass (FFM) using net underwater weight while taking into consideration the individual's residual volume.

Residual Volume (RV). The volume of air remaining in the lungs following a maximal expiration.

$50 \mathrm{ml}^{\mathrm{kgFFM}}{ }^{-1} \cdot \mathrm{min}^{-1}$. A minimum standard of which all participants must meet in order to establish a minimum fitness level, in order to resemble Forest Service standards.

Rested. No high intensity exertion in previous 24 hours and no exercise in previous 12 hours. 
Fasted. No caloric intake for at least 10 hours.

50-25-25 Diet. A dietary intake for the three days prior to heat stress trials consisting of $50 \%$ carbohydrates and the balance made up of protein and fat in an attempt to mimic a typical firefighter's diet out on the fire line.

Fluid Intake. Carbohydrate/Pla feedings, which is variable, based on a carbohydrate delivery of a $7 \%$ solution per $\mathrm{kg}$ FFM. Water ad libitium for initial trial (A) and duplication of that volume for second trial (B) for repeated measures statistical analysis.

Carbohydrate Feeding. Supplied in a solution according to FFM, ensuring equal intake for all participants based on metabolically actives, not simply body weight.

Exercise Intensity. $100 \%$ Ventilatory Threshold.

Heated Environment. The heat chamber will maintain a constant temperature of $39^{\circ} \mathrm{C}$ $\left( \pm 1^{\circ} \mathrm{C}\right)$ for each heat stress trial. 


\section{Chapter Two: Review of Literature}

\section{Research design of salivary Immunoglobulin A and exercise}

Results vary from studies investigating the effects exercise has on s-lgA levels ${ }^{16}$. Methodological differences between previous studies include variations in intensity, duration, saliva sample collecting protocol, expression of s-igA concentrations and environmental (including controlling for participant state of being). All of the previous sIgA studies reviewed established exercise intensities at set percentages of $\mathrm{VO}_{2 \max }$. Saliva sample collection has been received from whole mixed saliva ${ }^{20,34,35}$ or specific glands, e.g. parotid, ${ }^{31,54}$ with this collection being stimulated ${ }^{32,53}$ or unstimulated ${ }^{3,21,54}$. The fitness levels of sample populations have ranged from recreational/ sedentary/variable fitness level ${ }^{3,21,34,54}$ to elite fitness level ${ }^{20,33,54}$.

\section{Incidence of Upper Respiratory Tract Infections}

Several epidemiological studies ${ }^{24,28,43-45,48,49}$ have reported the effects of exercise on the risk of developing upper respiratory tract infections, emphasizing endurance training and endurance events such as marathons and ultra-endurance competitions. Peters: and Bateman ${ }^{48}$, Nieman, Nehlsen-Cannarella et al. ${ }^{46}$, Heath et al. ${ }^{24}$, among others, found an increased incidence of URTI's associated with higher intensity and/or longer duration endurance events and training. Nieman, Johanssen et al. ${ }^{45}$ assigned mildly obese females to walking or nonexercising groups. During this time, the exercising group had improved fitness, and increased natural killer cells with a lower incidence of URTI compared to their sedentary controls. This investigation concluded that intensity of exercise plays'a major role in immunosuppressive vs. immuno-enhancing activities.

\section{Salivary IgA and exercise}

A state of immunosuppression weakens the immune system. Due to the nature of sIgA's role in the mucosal immune system it is suggested that levels of s-lgA influence the battle against URTI's $20,31,35,54$. All of which investigated the effects of exercise on s- 
IgA resulting in decreased levels of s-IgA. However, the subjects fitness level,saliva collection protocols and intensities have varied among previous research. Studies have also demonstrated no change in s-lgA levels ${ }^{34,}{ }^{35}$ after sub-maximal exercise, also leading to the conclusion that intensity/duration (amount of physiological stress) plays a predominant role in depressed levels of s-lgA. It is generally accepted that higher intensities promote immunosuppressive episodes while lower intensities result in more individual responses.

\section{Carbohydrate supplementation and the immune system (s-IgA)}

Studies ${ }^{19 .} 41,42$ have shown that carbohydrate ingestion at regular intervals during strenuous exercise attenuates immunosuppression based on immune system markers. To our knowledge only one study' has demonstrated the attenuation of s-lgA depression with carbohydrate supplementation.

\section{Chapter Three: METHODOLOGY}

\section{Setting}

All physiological testing took place in the Human Performance Laboratory, McGill Hall \#121, The University of Montana.

\section{Participants}

Twelve recreationally active males $(n=6)$ and females $(n=5)$ served as participants.

Participants were healthy and free of prescribed medication. Prior to participation, each participant provided consent as approved by the University Internal Review Board.

\section{Preliminary Testing and Data Collection}

Preliminary testing included an informative session where testing methods were explained to each participant. Baseline measures of peak oxygen consumption (peak $\mathrm{VO}_{2}$ ) and body composition were obtained prior to the extended exercise sessions in the heat.

Peak $\mathrm{VO}_{2}$ treadmill test 
Peak oxygen uptake was measured using a graded maximal treadmill test (Quinton Q65 treadmill) and open-circuit spirometry (Modified ParvoMedics system with an LB-2 $\mathrm{CO}_{2}$ Gas Analyzer; OM-11 $\mathrm{O}_{2}$ Analyzer, and heated Hans-Rudolph pneumotach). Criteria for peak VO2 was established with matching two of three criteria: base levels of 1) RER (1.1) 2)\% of estimated maximal heart rate (min. $90-95 \%$ maximal HR) 3) Decreased rate of $\mathrm{O} 2$ consumption (plateau). Prior to each test, the metabolic system was calibrated using a three-liter calibration syringe (Spirometrics, Inc.) and medical gases of known concentration $\left(5.17 \% \mathrm{CO}_{2} ; 15.2 \% \mathrm{O}_{2} ;\right.$ Balance $\left.\mathrm{N}_{2}\right)$. Metabolic data was recorded in fifteen-second intervals. From the baseline data, a Ventilatory Threshold (VT) was established for each participant using the technique of Gaskill et al. ${ }^{15}$. Exercise intensity for the extended exercise trials was established as the treadmill speed and grade associated with $100 \%$ of the calculated speed and grade at the ventilatory threshold. Female participants performed all testing at the end of menses (preliminary testing) and during the early follicular phase (Trials $A$ and $B$ ).

\section{Body Composition}

Body composition was assessed using hydrostatic weighing with a digital scale (Exertech, Dresbach, MN) at estimated residual volume ${ }^{30}$. Net underwater weight was calculated from 100 sampling intervals over a 1.5 second recording period. Multiple underwater trials were repeated to establish no less than three measures within 100 grams and an average taken.

\section{Testing Protocol}

Participants recorded food intake for 3 days prior to each test session, choosing foods to maintain a dietary intake of $50 \%$ carbohydrates with the balance consisting of protein and fat. Nutrient intake was assessed using a food processor program for Windows by ESHA Research (Salem, OR). Participants were required to track nutrient and water 
intake, as well as activity, during the $5 \mathrm{hrs}$ between the $1 \mathrm{hr}$ and $6 \mathrm{hr}$ sample times of trial A and subsequently duplicate these variables for trial B.

\section{Exercise Testing}

For each test session the participants reported to the Human Performance Laboratory at 7:00 a.m. in a minimum 10-hour fasted and rested condition. Participants were required to have refrained from intensive exercise for twenty-four hours prior to the testing and have avoided all exercise for 12-15 hours before testing. The participants were also free of symptoms related to infection, specifically upper respiratory infections. Immediately after arrival, participants were encouraged to void their bladder prior to obtaining a nude body weight (Befour B1digital scale, model \# PS6600T). Participants inserted core temperature probe (YSI Precision $4000 \mathrm{~A}$ Thermometer) to a depth of $10 \mathrm{~cm}$, which was kept in place for temperature recording throughout the extended heat-stressed exercise bout. An intravenous teflon catheter (18 or 20 gauge) was placed in an antecubital vein and kept patent using a continuous saline drip (.45 normal saline). After a 3-5 minute rest period upon IV insertion, a baseline blood sample was obtained.

Prior to treadmill test administration each participant produced a saliva sample in a four minute (-4 - 0 minutes), unstimulated collection procedure via expectoration. Samples were stored at $-80^{\circ} \mathrm{C}$ until subsequent analysis. Following the initial sample collections, trial A's extended exercise sessions were initiated at an intensity equal in grade and treadmill belt speed to $100 \%$ of the baseline VT. Each extended exercise session included 120 minutes of treadmill walking in an environmental heat chamber $\left(39^{\circ} \mathrm{C}\right)$. Modifications to intensity, when absolutely necessary, were made in trial $A$ and documented so as to ensure completion of 120 minutes heat-stressed exercise bout and subsequent duplication in trial $\mathrm{B}$. 
Additional saliva samples were obtained at immediately post-exercise, $1 \mathrm{hr}$ postexercise and $6 \mathrm{hr}$ post-exercise sample times(-4-0, 120-124 minutes, $60-64$ post testing and $6 \mathrm{hr}$ post testing). Following the test initiation, blood sampling, heart rate (HR) monitoring, ratings of perceived exertion (RPE) according to Borg et al. ${ }^{4}$, core temperatures and carbohydrate or Pla feedings occurred at 30-minute intervals $(0,30$, $60,90,120$ minutes). HR values determined using Polar, chest-strap HR monitors. Carbohydrate was supplied according to fat free mass (FFM) to give $\mathrm{CHO}^{-}$by $\mathrm{gkg} \mathrm{FFM}^{-}$

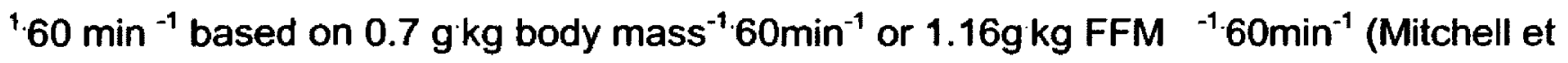
al, 1989) delivery ensuring equal intake for males and females according to energy requiring tissues. $\mathrm{CHO}$ and Pla delivery followed a double blind protocol. All trials were conducted at the same time of day to control for any diurnal effects on s-lgA levels ${ }^{27}$.

Expired air samples were obtained for gas analysis in 5-minute intervals every 30 minutes $(0-5,25-30,55-60,85-90,115-120$ minutes) using the same metabolic system and procedure discussed above. Dehydration ${ }^{9}$ was controlled for with fluid intake within the $7 \% \mathrm{CHO}$ solution at 30-minute intervals and water ad libitium during trial $\mathrm{A}$ and subsequent water intake duplication during trial B. Fluid intake was measured by tracking $\mathrm{CHO}$ solution ingested, water intake and saline infused during testing. Fluid output was measured via urine collection during exercise trial and prior to measure of nude body weight post exercise, including volumes collected at 60 (if needed) and 120 minutes of each test.

\section{Blood Sampling}

During each trial, a total of six blood samples were obtained $(0,30,60,90,120$ minutes; 5-8 $\mathrm{ml} / \mathrm{draw}$ ). Samples were obtained from an antecubital vein with participants supine for baseline and post exercise samples, while the sample collection during testing was obtained with participants straddling treadmill belt for minimal delay of exercise. Four $\mathrm{ml}$ of the 0,60 , and 120 -minute blood draws were placed into a sterile Vacutainer tube 
containing $K_{3} E D T A$. These samples were set-aside at room temperature until subsequent analyses immediately post exercise (complete blood count - CBC, Western Montana Clinic). CBC analyses were completed within 4 hours post collection. At 30 , 60,90 , and 120 minutes $500 \mu l$ of the remaining blood drawn will be immediately transferred to a tube, mixed with $1000 \mu 17 \%$ perchloric acid and spun down. Samples were stored at $-30^{\circ} \mathrm{C}$ until subsequent analysis. The perchloric acid extract was used for the glucose, glycerol and lactate assays. Glucose, glycerol and lactate concentrations were assayed using a Spectronic 401 spectrophotometer (Milton Roy) and were analyzed using an enzymatic spectrophotometric technique (glucose Sigma assay procedure \#16-UV; glycerol Sigma assay procedure \#337). Lactate was analyzed according to Lowry (1976). All metabolite values were corrected for plasma volume change per individual participant.

\section{Saliva Sampling}

Each trial consisted of four, four-minute saliva collections $(-4-0,120-124$ minutes, $60-64$ minutes post, and $6 \mathrm{hr}$ post exercise). Unstimulated whole saliva was collected by expectoration into $15-\mathrm{ml}$ plastic, sterilized tubes for the four-minute collection period. The sample was sealed and stored at $-80^{\circ} \mathrm{C}$ until analysis. Saliva weight was measured to the nearest $.01 \mathrm{~g}$, and saliva total protein was quantified using the Coomassie protein assay reagent, a modification of the Bradford Coomassie ${ }^{\oplus}$ dye binding colorimetric method. Salivary IgA was measured by enzyme linked immunosorbent assay according to the procedures of the Hunter Immunology Unit (royal Newcastle Hospital, Newcastle, NSW, Australia). The data was expressed as concentration of slgA $\left(\mu \mathrm{gml}^{-1}\right)$, concentration of slgA relative to total protein concentration $\left(\mu \mathrm{g} \cdot \mathrm{min}^{-1}\right)$, and slgA secretion rate $\left(\mu \mathrm{g} \cdot \mathrm{min}^{-1}\right)$. The saliva flow rate $\left(\mu / \mathrm{min}^{-1}\right)$ was calculated from measurement of the saliva divided by the collection time. Salivary density was assumed 
to be $1.00 \mathrm{~g} \mathrm{ml}^{-1}$. Saliva IgA secretion rate was calculated by multiplying saliva flow rate by saliva IgA concentration.

\section{Statistical Analysis}

Data are expressed as mean \pm SEM. A student's t-test was used to analyze actual vs. expected \%VT across trials. Salivary IgA measurements were analyzed using a 2-way repeated measures ANOVA $(2 \times 4$, trial $X$ time). A prior planned comparisons on the trial $\mathrm{X}$ time interaction including comparisons between trials at each time point and comparisons from pre to each time point within each trial. Experiment-wise alpha was adjusted to minimize type I error because the desired number of comparisons exceeded $k-1(k-1=7 ;(0.05 \times 7) / 10=0.035)$. Lactate, glucose, $H R$ and core temperature values were analyzed using a 2-way repeated measures ANOVA $(2 \times 5$, trial $X$ time $)$. A prior planned comparisons on the trial $X$ time interaction including comparisons between trials at each time point and comparisons from pre to each time point within each trial. Experiment-wise alpha was adjusted to minimize type I error because the desired number of comparisons exceeded $k-1(k-1=9 ;(0.05 \times 9) / 13=0.0346) . \quad C B C$ values were analyzed using a 2-way repeated measures ANOVA $(2 \times 3$, trial $X$ time $)$. A prior planned comparisons on the trial $X$ time interaction including comparisons between trials at each time point and comparisons from pre to each time point within each trial. Experiment-wise alpha was adjusted to minimize type l error because the desired number of comparisons exceeded $k-1(k-1=5 ;(0.05 \times 5) / 7=0.037)$.

\section{Chapter 4: RESULTS}

\section{Subject Characteristics}

All of the participants $(n=11)$ of this study were recreationally active and currently involved in regular exercise. All female participants $(n=5)$ performed both exercise trials in the early follicular phase of their menstrual cycle (within the first seven days post menses). Descriptive data are shown in Table 1. 
The average exercise intensity was not significantly different for the two trials ( $99.4 \%$ and $97.75 \%$ of $\mathrm{VO}_{2 \mathrm{VT}}$ for the Pla and $\mathrm{CHO}$ trials, respectively, see Table 2). There were no significant differences in the average values for oxygen consumption, exercise intensity, RER, sweat rate, percent change in plasma volume or change in body weight across trials (see Table 2). Values for HR, CT and RPE are presented in Table 3. Although there were no significant differences between the trials, each trial showed a significant increase in HR, CT and RPE at each time point compared to the initial 5minute measures (Table 3).

\section{Metabolites}

Metabolite analyses are presented for only 10 participants as a result of sampling difficulty with one male subject. Multiple comparison analysis revealed significant differences in plasma glucose levels during the $\mathrm{CHO}$ trial at $30,60,90$, and 120 minutes when compared to baseline (Figure 1). However, plasma glucose levels during the Pla trial revealed a significant difference from baseline at the 30-minute sample time only. Multiple comparison analysis further revealed a significantly higher plasma glucose during the $\mathrm{CHO}$ trial at 120 minutes in comparison to the Pla trial. (Figure 1).

There was a significant increase in plasma lactate levels during the $\mathrm{CHO}$ and $\mathrm{Pla}$ trials at $30,60,90$, and 120 minutes compared to baseline (Table 4). Plasma lactate was significantly lower during the $\mathrm{CHO}$ trial at 60,90 , and 120 minutes compared to the Pla trial (Table 4). Similarly, there was a significant increase in plasma glycerol levels during the $\mathrm{CHO}$ and $\mathrm{Pla}$ trials at $30,60,90$, and 120 minutes compared to baseline (Table 4). However, there were no significant differences between Pla and $\mathrm{CHO}$ trials (Table 4). 


\section{Blood immune markers}

All blood immune marker analyses ( $\mathrm{CBC}$ analysis) were performed using 10 subjects due to sample clotting, which occurred in one male's sample. Multiple comparison analysis revealed a significant increase in WBC, Lymphocytes, Neutrophils, and Monocytes during both the $\mathrm{CHO}$ and Pla trials at the post-exercise sample time when compared to baseline, while Eosinophils showed no significant difference over time (Table 5). There were no significant differences between $\mathrm{CHO}$ and $\mathrm{Pla}$ for any of the blood immune markers at any time point (Table 5). All values were corrected for any change in plasma volume.

\section{Salivary immune markers}

All salivary IgA analyses were done without two participants $(n=9)$ due to viscous saliva and a missed sample. Multiple comparison analysis revealed no significant change in salivary flow rate $\left(\mathrm{ml} \mathrm{min}^{-1}\right)$ compared to rest or across trials (Figure 2). A significant decrease in the concentration of s-lgA $\left(\mu \mathrm{g} \cdot \mathrm{ml}^{-1}\right)$ was seen during the $\mathrm{CHO}$ trial at $1 \mathrm{hr}$ and $6 \mathrm{hr}$ post exercise compared to baseline. However, the Pla trial demonstrated a significant decrease in s-lgA $\left(\mu \mathrm{g} \mathrm{ml}^{-1}\right)$ at only $6 \mathrm{hr}$ post exercise (Figure 3). Figure 3 also shows that there were no differences across trials for s-lgA concentration $\left(\mu \mathrm{g} \mathrm{ml}^{-1}\right)$.

Similar to s-lgA concentration $\left(\mu \mathrm{g} \cdot \mathrm{ml}^{-1}\right)$, multiple comparison analysis revealed a significant decrease in IgA secretion rate $\left(\mu \mathrm{g} \mathrm{min}^{-1}\right)$ during the $\mathrm{CHO}$ and $\mathrm{Pla}$ trials (pre vs. $6 \mathrm{hr}$ post) (Figure 4). A significant decrease in IgA secretion rate ( $\left.\mu \mathrm{g} \cdot \mathrm{min}^{-1}\right)$ was also noted during the $\mathrm{CHO}$ trial at $1 \mathrm{hr}$ post exercise compared to baseline. However, there were no significant differences between the $\mathrm{CHO}$ and Pla trials.

This present data revealed a significant but transient increase in salivary protein concentration $\left(\mathrm{mg} \mathrm{ml}^{-1}\right)$ at the post sample times for both the $\mathrm{CHO}$ (baseline=2.69 $\mathrm{mg} \pm$ 0.44 vs. post-exercise $=5.34 \mathrm{mg} \pm 0.92$ ) and $\mathrm{Pla}$ (baseline $=2.82 \mathrm{mg} \pm 0.52$ vs. post- 
exercise $=5.02 \mathrm{mg} \pm 0.62$ ) trials. However, there were no significant differences across the trials for protein concentration.

Figure 5 shows the change in protein secretion rate for each trial. There was a significant decrease in protein secretion rate $\left(\mathrm{mg} \mathrm{min}^{-1}\right)$ at the immediate post, $1 \mathrm{hr}$ and 6 hr post sample times during the $\mathrm{CHO}$ trial. However, during the Pla trial, there was a significant decrease in protein secretion rate $\left(\mathrm{mg} \mathrm{min}^{-1}\right)$ at the $6 \mathrm{hr}$ post sample time only. The $\mathrm{CHO}$ trial also demonstrated significantly lower protein secretion rates $\left(\mathrm{mg} \mathrm{min}^{-1}\right)$ at the immediate post and $1 \mathrm{hr}$ post sample times in comparison with the Pla trial.

Figure 6 demonstrates a significantly lower $\lg A$ to protein ratio $(\mu \mathrm{g} \operatorname{lgA} \mathrm{mg}$ protein $^{-1}$ ) during the $\mathrm{CHO}$ trial at the immediate post, $1 \mathrm{hr}$ and $6 \mathrm{hr}$ post exercise sample times in comparison to baseline values. The Pla trial also demonstrated a significant decrease in this ratio ( $\mu \mathrm{g} \operatorname{lgA} \mathrm{mg}$ protein $^{-1}$ ) for the immediate post and $6 \mathrm{hr}$ post exercise sample times in comparison to baseline (Figure 6). There were no significant differences between the $\mathrm{CHO}$ and Pla trials.

\section{Chapter 4: DISCUSSION}

The primary finding of the current study indicates that liquid $\mathrm{CHO}$ supplementation does not attenuate the ensuing alterations of immunity in response to an acute ( $2 \mathrm{hr}$ ) bout of exercise in the heat. In the current study, the combination of heat exposure, exercise intensity and duration resulted in maximal fatigue and altered immune markers (CBC and salivary data). Although previous research has evaluated the s-IgA marker in response to extended exercise bouts ( 1 to $2 \mathrm{hr}$ ) and/or competitive endurance events ${ }^{1}$. $29,34,53,54$, only one study has evaluated the s-IgA marker in response to short term exercise (30 minutes) in the heat ${ }^{26}$. In addition, to our knowledge only two investigations have incorporated liquid $\mathrm{CHO}$ supplementation during exercise in hopes of attenuating the s-lgA response ${ }^{1.2}$. However, the effectiveness of liquid $\mathrm{CHO}$ 
supplementation on the s-IgA marker during extended exercise in the heat has not been evaluated.

According to a recent review by Gleeson ${ }^{16}$, the disparity in the literature for the exercise-induced changes in s-lgA is partly due to inconsistent exercise protocols and non-standardized data representation. In the current study, the exercise intensity was normalized to each subjects VT in an attempt to minimize variations the physiological response across subjects (Table 2). In addition, the physiological responses at VT are more closely related to training status and exercise performance compared to an arbitrary percentage of $\mathrm{VO}_{2 \mathrm{PEAK}}{ }^{8}$.

In the current study, plasma glucose concentration was similar between trials until $120 \mathrm{~min}$. This suggests an impaired rate of gastric emptying in response to the high ambient temperature of $39^{\circ} \mathrm{C}$ or an increase in hepatic glucose production in response to the heat regardless of $\mathrm{CHO}$ ingestion. In agreement with the present study, Neufer et al. ${ }^{38}$ reported that gastric emptying is markedly reduced in individuals performing treadmill exercise in a hot $\left(49^{\circ} \mathrm{C}\right)$ as compared with neutral $\left(18^{\circ} \mathrm{C}\right)$ environment. Furthermore, high ambient temperatures may inhibit gastric emptying by reducing splanchnic blood flow ${ }^{50}$ and or gastric motility ${ }^{55}$. Previous research has demonstrated that exercise intensity can influence gastric emptying ${ }^{13}$. Exercise performed at or below $70 \% \mathrm{VO}_{2 \mathrm{PEAK}}$ does not apparently inhibit gastric emptying in comparison to the delay noted during exercise above this intensity. In the current study, subjects averaged $57 \%$ and $56 \%$ of $\mathrm{VO}_{2 \text { PEAK }}$ during the Pla and $\mathrm{CHO}$ trials, respectively. Therefore, the apparent delay in gastric emptying noted in the present investigation cannot be fully explained by the intensity of exercise. 
Our $7 \%$ glucose solution ${ }^{36}$ and volume ${ }^{52}$ fits within the suggested ranges known to allow adequate gastric emptying and fluid delivery, at room temperature $\left(22^{\circ} \mathrm{C}\right)$. In comparison, one previous study has suggested that a $10 \% \mathrm{CHO}$ solution consumed during exercise in a $35^{\circ} \mathrm{C}$ environment $\left(65 \% \mathrm{VO}_{2}\right.$ peak, 120 minutes of treadmill running) did not compromise gastric emptying ${ }^{47}$. The type of $\mathrm{CHO}$ within the solution in combination with the heat may act to inhibit gastric emptying ${ }^{37}$, despite the beneficial effects of a high volume. These studies have suggested that glucose solutions inhibited gastric emptying more dramatically in comparison to fructose solutions when presented in equimolar solutions. Although the conditions are favorable for unimpeded gastric emptying in lower ambient temperatures, the current study is suggesting that hot environments may slow gastric emptying and thus absorption, regardless of intake volume, exercise intensity, or solution concentration

Hargreaves et al. ${ }^{22}$ has demonstrated that hepatic glucose production is increased during the last $30-\mathrm{min}$ of a $40-\mathrm{min}$ cycle ergometer exercise bout in a $40^{\circ} \mathrm{C}$ environment. Interestingly, there were no differences in the rate of glucose disappearance in response to the heat stress trial. Collectively, these data support the delayed response in plasma glucose noted in the present investigation.

In the current study, the salivary flow rate did not change in response to exercise. However, s-lgA concentration was suppressed for both post-exercise sample times $(1 \mathrm{hr}$ and $6 \mathrm{hr}$ ) during the $\mathrm{CHO}$ trials and for the $6 \mathrm{hr}$ post-exercise sample time during the $\mathrm{Pla}$ trials, with no significant differences between trials. Although there was a trend towards an increase in the $6 \mathrm{hr}$ post salivary flow rate $\left(\mathrm{ml} / \mathrm{min}^{-1}\right.$, above baseline), the values were not statistically significant. A concomitant significant decrease in s-lgA concentration $\left(\mu \mathrm{g} \mathrm{m} \mathrm{ml}^{-1}\right)$ resulted in a significant decrease in the $\mathrm{lgA}$ secretion rate at the $6 \mathrm{hr}$ post sample time during both the $\mathrm{CHO}$ and Pla trials. These results are in contrast to a 
similar $\mathrm{CHO}$ feeding study ${ }^{1}$ in which mean $\operatorname{lgA}$ secretion rates $\left(\mathrm{ml} / \mathrm{min}^{-1}\right)$ demonstrated a slight but non-significant increase. These differences may be due to the possible contribution of a heat-induced inhibition of gastric emptying or simply an effect of the $40^{\circ} \mathrm{C}$ ambient temperature.

Interestingly, the combination of a possible heat-induced inhibition of gastric emptying and a heat-induced increase in fluid loss theoretically mimics the study of Bishop et al.'. Bishop has suggested that the responses of salivary $\lg A$ are mostly affected by changes in fluid balance. Bishop et al. ${ }^{7}$ has further suggested that the consumed fluid volume has a more dramatic influence on the s-lgA and flow rate than the $\mathrm{CHO}$ content of the consumed fluid. Expounding on this statement, these findings may indicate that fluid balance and core temperature as a reflection of ambient temperature are more critical at influencing the s-IgA marker. Nielsen ${ }^{39}$ suggested that an elevated core temperature is the ultimate cause of fatigue due to heat stress and that this may be the major contributor to altered immune states. Therefore, the combination in the present investigation may further exacerbate the process of compromised immunity. However, the process of $\mathrm{CHO}$ or $\mathrm{Pla}$ feeding along with ad libitium water intake resulted in minimal changes in plasma volume and body mass.

The current study revealed significant decreases in s-lgA concentration $\left(\mu{\mathrm{g} \mathrm{m}{ }^{-1}}^{-1}\right)$ during both the $\mathrm{CHO}$ and $\mathrm{Pla}$ trials compared to rest without finding a significant change between the $\mathrm{CHO}$ and Pla trials. This significant decrease in s-lgA concentration is in contrast to the increase noted by Bishop ef al. ${ }^{1}$. In addition, our results indicate significant decreases in IgA secretion rate (Figure 4) during both the $\mathrm{CHO}$ and Pla trials, demonstrating further alteration of the immune marker. The contrast with Bishop et al. indicate an acute, yet exacerbated immune response to prolonged exercise in the heat, which is not attenuated with the addition of liquid carbohydrate. 
Correcting s-lgA concentration for total protein concentration may be misleading when the concurrent alteration in protein secretion rate does not parallel the alteration in s-lgA secretion rate. In addition, there is evidence stemming from past research indicating that protein secretion, predominantly amylase ${ }^{56}$, increases during prolonged exercise $^{3}$. Interestingly, as can be seen in Figure 5 , protein secretion in the present study decreased significantly in both trials and is the only saliva related variable, which revealed a difference across trials. In the current study, the $\mathrm{CHO}$ trial demonstrated a decrease in protein secretion $\left(\mathrm{mg} \mathrm{min}^{-1}\right)$ at the post exercise time point and throughout recovery. In contrast, the Pla trial demonstrated significantly lower values at the $6 \mathrm{hr}$ post sample time in comparison to baseline values. Additionally, protein secretion rate was significantly lower at the $1 \mathrm{hr}$ post sample time during the $\mathrm{CHO}$ trial compared to the Pla trial. As previously discussed, this interaction may be due to an exaggerated physiological response caused by a compounding effect of supplemental $\mathrm{CHO}$ during exercise at a high ambient temperature.

Interestingly, there were no significant changes the salivary flow rate in our study. This is similar to the data of Bishop et al. ${ }^{1}$. Physical stress causes a stimulation of the sympathetic nervous system and a subsequent decrease in blood flow to the gut, leaving a majority of the blood flow to respond to the needs of the working muscles. The blood flow restriction includes the salivary glands, leading to decreased salivary secretion during exercise ${ }^{6}$. Despite the hot ambient temperature (likely causing an increase in skin blood flow), there were no significant changes in salivary flow rate over time during the $\mathrm{CHO}$ or Pla trials. This may in part be explained by the high ad libitium water intake, which, maintained close to normal hydration. Although this study did not reveal a significant change in saliva flow rate, the $\mathrm{CHO}$ trial did reveal a trend of attenuating any decrease in flow compared to the Pla trials. Therefore, the proposed inhibition of gastric 
emptying may minimize the suggested benefits of supplemental liquid $\mathrm{CHO}$ to salivary flow'.

Overall, the results of the current study maintain that $\mathrm{CHO}$ feedings (provided at an average rate of $1.16 \mathrm{~g} \cdot \mathrm{kg} \mathrm{FFM}^{-1} \cdot \mathrm{hr}^{-1}$ in a $7 \%$ solution) have no effect on attenuating acute alterations in immune function (based on changes in blood and salivary markers) during or after extended exercise in the heat. These results further demonstrate that the benefits of supplemental nutrition may be best achieved outside of the exercise bout in hot environments when gastric emptying is impaired. Further research should determine the effects of post-exercise $\mathrm{CHO}$ and nutrient intake on the restoration of immune function. 


\section{REFERENCES}

1. Bishop, N. C., A. K. Blannin, E. Armstrong, M. Rickman, and M. Gleeson. Carbohydrate and fluid intake affect the saliva flow rate and IgA response to cycling. Med. Sci. Sports Exerc. 32:2046-2051, 2000.

2. Bishop, N. C., A. K. Blannin, P. J. Robson, N. P. Walsh, and M. Gleeson. The effects of carbohydrate supplementation on immune responses to a soccerspecific exercise protocol. J. Sports Sci. 17:787-796, 1999.

3. Blannin, A. K., P. J. Robson, N. P. Walsh, A. M. Clark, L. Glennon, and M. Gleeson. he effect of exercising to exhaustion at different intensities on saliva Immunoglobulin A, protein and electrolyte secretion. Int. J. Sports Med. 19:547$552,1998$.

4. Borg, G. A. Psychophysical bases of perceived exertion. Med Sci Sports Exerc. 14:377-381., 1982.

5. Brandtzaig, P., E. S. Baekkavold, I. N. Farstad, F. L. Jahnsen, F. E. Johansen, E. $M$. Nilson, and T. Yamanaka. Regional specialization in the mucosal immune system; what happens in the micocompartments? Immunol. Today. 20:141-151, 1999.

6. Chicharro, J. L., A. Lucia, M. Peraz, A. F. Vaquero, and R. Urena. Saliva composition and exercise. Sports Med. 26:17-27, 1998.

7. Coggan, A. R., W. M. Kohrt, R. J. Spina, J. P. Kirwan, D. M. Bier, and J. O. Holloszy. Plasma glucose kinetics during exercise in subjects with high and low lactate thresholds. J. Appl. Physiol. 73:1873-1880, 1992.

8. Coyle, E. F., A. R. Coggan, M. K. Hopper, and T. J. Walters. Determinants of endurance in well-trained cyclists. J. Appl. Physiol. 64:2622-2630, 1988.

9. Coyle, E. F. and S. J. Montain. Benefits of fluid replacement with carbohydrate during exercise. Med. Sci. Sports Exerc. 24:S324-S330, 1992.

10. Cunningham-Rundles, $\mathrm{S}$. Effects of nutritional status on immunological function. J. Am. Clin. Nutr. 35:1202-1210, 1982.

11. Deinzer, R., C. Kleineidam, R. Stiller-Winkler, H. Idel, and D. Bachg. Prolonged reduction of salivary immunoglobulin $A$ (slgA) after a major academic exam. Int. J. Psychophysiol. 37:219-232, 2000.

12. Febbraio, M. A., J. M. Parkin, J. Baldwin, S. Zhao, and C. M.F. Effect of ambient temperature on metabolic indices of fatigue during prolonged exercise. Med. Sci. Sports Exerc. 28:S180, 1996.

13. Fordtran, J. S. and B. Saltin. Gastric emptying and intestinal absorption during prolonged severe exercise. J. Appl. Physiol. 23:331-335, 1967.

14. Galloway, S. D. R. and R. J. Maughan. Effects of ambient temperature on the capacity to perform prolonged exercise in man. J. Physiol. 489:35P-36P, 1995.

15. Gaskill, S. E., B. C. Ruby, A. J. Walker, O. A. Sanchez, R. C. Serfass, and A. S. Leon. Validity and reliability of combining three methods to determine ventilatory threshold. Med. Sci. Sports Exerc. In review.

16. Gleeson, M. Mucosal immunity and respiratory illness in elite athletes. Int. J. Sports Med. 21:S33-S43, 2000.

17. Gleeson, M. and N. C. Bishop. Elite athlete immunology: Importance of nutrition. Int. J. Sports Med. 21:S44-S50, 2000.

18. Gleeson, M. and N. C. Bishop. Modification of immune responses to exercise by carbohydrate, glutamine and anti-oxidant supplements. Immunol. Cell Biol. 78:554-561, 2000. 
19. Gleeson, M., A. K. Blannin, N. P. Walsh, N. C. Bishop, and A. M. Clark. Effects of low- and high-carbohydrate diets on the plasma glutamine and circulating leukocyte responses to exercise. In. J. Sport Nutr. 8:49-59, 1998.

20. Gleeson, M., W. A. McDonald, A. W. Cripps, D. B. Pyne, R. L. Clancy, and P. A. Fricker. The effect of immunity of long-term intensive training in elite swimmers. Clin. Exp. Immunol. 102:210-216, 1995.

21. Gleeson, M., W. A. McDonald, D. B. Pyne, A. W. Cripps, J. L. Francis, P. A. Fricker, and R. I. Fricker. Salivary IgA levels and infection risk in elite swimmers. Med. Sci. Sports Exerc. 31:67-73, 1999.

22. Hargreaves, M., D. Angus, K. Howlett, N. M. Conus, and M. Febbraio. Effect of heat stress on glucose kinetics during exercise. J Appl Physiol. 81:1594-1597., 1996.

23. Hawley, J. A., S. C. Dennis, E. H. Lindsey, and T. D. Noakes. Nutritional practices of athletes: Are they sub-optimal? J. Sports Sci. 13:S75-S81, 1995.

24. Heath, G. W., E. S. Ford, T. E. Craven, C. A. Macera, K. L. Jackson, and R. R. Pate. Exercise and the incidence of upper respiratory tract infections. Med. Sci. Sports Exerc. 23:152-157, 1991.

25. Henson, D. A., D. C. Nieman, A. D. Blodgett, D. E. Butterworth, A. Utter, J. M. Davis, G. Sonnenfeld, D. S. Morton, O. R. Fagoaga, and S. L. NehlsenCannarella. Influence of exercise mode and carbohydrate on the immune response to protonged exercise. Int. J. Sport Nutr. 9:213-228, 1999.

26. Housh, T. J., G. O. Johnson, D. J. Housh, S. L. Evans, and G. D. Tharp. The effect of exercise at various temperatures on salivary levels of Immunoglobulin A. Int. J. Sports Med. 12:498-500, 1991.

27. Hucklebridge, F., A. Clow, and P. Evans. The relationship between salivary secretory immunoglobulin A and cortisol: neuroendocrine response to awakening and the diurnal cycle. Int. J. Psychophysiol. 31:69-76, 1998.

28. Linde, F. Running and upper respiratory infections. Scand. J. Sports Sci. 9:21-23, 1987.

29. Ljungberg, G., T. Ericson, B. Ekblon, and D. Birkhed. Saliva and marathon running. Scand. J. Med. Sci. Sports. 7:214-219, 1997.

30. Lohman, T. G. Advances in Body Composition. Champaign, IL: Human Kinetics Publishers, 1992

31. Mackinnon, L. T., T. W. Chick, A. van As, and T. B. Tomasi. The effect of exercise on secretory and natural immunity. Adv. Exp. Med. Biol. 216A:869-876, 1987.

32. Mackinnon, L. T., Chick, T.W., van As, A., and Tomasi, T.B. Decreased secretory immunoglobulins following intense endurance exercise. Sports Training in Medicine and Rehabilitation. 1:1-10. 1989. Decreased secretory immunoglobulins following intense endurance exercise. Sports Training Med. Rehabilitation. 1:1-10, 1989.

33. Mackinnon, L. T., E. Ginn, and G. J. Seymour. Decreased salivary immunoglobulin A secretion after intense interval exercise in elite kayakers. Eur. J. Appl. Physiol. 67:180-184, 1993.

34. Mackinnon, L. T. and S. Hooper. Mucosal (secretory) immune system responses to exercise of varying intensity and during overtraining. In. J. Sports Med. 15:S179-S183, 1994.

35. McDowell, S. L., R. A. Hughes, R. J. Hughes, T. J. Housh, and G. O. Johnson. The effect of exercise training on salivary immunoglobulin $A$ and cortisol responses to maximal exercise. Int. J. Sports Med. 13:577-580, 1992. 
36. Mitchell, J. B., D. L. Costill, J. A. Houmard, W. J. Fink, D. D. Pascoe, and D. R. Pearson. Influence of carbohydrate dosage on exercise performance and glycogen metabolism. J. Appl. Physiol. 67:1843-1849, 1989.

37. Neufer, P. D., D. L. Costill, W. J. Fink, J. P. Kirwan, R. A. Fielding, and M. G. Flynn. Effects of exercise and carbohydrate composition on gastric emptying. Med. Sci. Sports Exerc. 18:658-662, 1986.

38. Neufer, P. D., A. J. Young, and M. N. Sawka. Gastric emptying during exercise: effects of heat stress and hypohydration. Eur. J. Appl. Physiol. 58:433-439, 1989.

39. Nielsen, B. Heat stress and acclimation. Ergonomics. 37:49-58, 1994.

40. Nieman, D. C. Exercise, upper respiratory tract infection, and the immune system. Med. Sci. Sports Exerc. 26:128-139, 1994.

41. Nieman, D. C., O. R. Fagoaga, D. E. Butterworth, B. J. Warren, A. Utter, J. M. Davis, D. A. Henson, and S. L. Nehlsen-Cannarella. Carbohydrate supplementation affects blood granulocyte and monocyte trafficking but not function after $2.5 \mathrm{~h}$ running. Am. J. Clin. Nutr. 66:153-159, 1997.

42. Nieman, D. C., D. A. Henson, E. B. Garner, D. E. Butterworth, B. J. Warren, A. Utter, J. M. Davis, O. R. Fagoaga, and S. L. Nehlsen-Cannarella. Carbohydrate affects natural killer cell redistribution but not function after running. Med. Sci. Sports Exerc. 20:1318-1324, 1997.

43. Nieman, D. C., D. A. Henson, G. Gusewitch, B. J. Warren, R. C. Dotson, D. E. Butterworth, and S. L. Nehlsen-Cannarella. Physical activity and immune function in elderly women. Med. Sci. Sports Exerc. 25:823-831, 1993.

44. Nieman, D. C., L. M. Johanssen, and J. W. Lee. Infectious episodes in runners before and after a roadrace. J. Sports Med. Phys. Fitness. 29:289-296, 1989.

45. Nieman, D. C., L. M. Johanssen, J. W. Lee, and K. Arabatzis. Infectious episodes in runners before and after the Los Angeles Marathon. J. Sports Med. Phys. Fitness. 30:316-328, 1990.

46. Nieman, D. C., S. L. Nehlseri-Cannarella, P. A. Markoff, A. J. Balk-Lamberton, H. Yang, D. B. Chritton, J. W. Lee, and K. Arabatzis. The effects of moderate exercise training on natural killer cells and acute upper respiratory tract infections. Int. J. Sports Med. 11:467-473, 1990.

47. Owen, M. D., K. C. Kregel, P. T. Wall, and C. V. Gisolfi. Effects of ingesting carbohydrate beverages during exercise in the heat. Med. Sci. Sports Exerc. 18:568-575, 1986.

48. Peters, E. M. and B. E.D. Respiratory tract infections: an epidemiological survey. S. Afr. Med. J. 64:582-584, 1983.

49. Peters, E. M., J. M. Goetzsche, B. Grobbelaar, and T. D. Noakes. Vitamin C supplementation reduces the incidence of postrace symptoms of upperrespiratory-tract infection in ultra-marathon runners. Am. J. Clin. Nutr. 57:170174, 1993.

50. Rowell, L. B., G. L. Brengelmann, J. R. Blackmon, R. D. Twill, and K. F. Splanchic blood flow and metabolism in heat-stressed man. J. Appl. Physiol. 24:475-484, 1968.

51. Ruby, B. C., T. C. Shriver, T. W. Zderic, B. Sharkey, C. Burks, and S. Tysk. Total energy expenditure during arduous wildfire suppression using doubly labeled water. Med. Sci. Sports Exerc. In review.

52. Ryan, A. J., T. L. Bleiler, J. E. Carter, and C. V. Gisolfe. Gastric emptying during prolonged cycling exercise in the heat. Med. Sci. Sports Exerc. 21:51-58, 1989.

53. Steerenberg, P. A., I. A. van Asperen, A. van Nieuw Amerongen, J. Biewenga, D. Mol, and G. Medema. Salivary levels of immunoglobulin A in triathletes. Eur. $J$. Oral Sci. 105:305-308, 1997. 
54. Tomasi, T. B., F. B. Trudeau, D. Cservinski, and S. Erredge. Immune parameters in athletes before and after strenuous exercise. J. Clin. Immunol. 2:173-178, 1982.

55. Tsuchiya, K. and M. Iriki. Effects of spinal cord cooling and heating on gastrointestinal motility in spinal-intact and acutely spinalized dogs. Italian $\mathrm{J}$. Gastroenterol. 12:255-259, 1980.

56. Walsh, N. P., A. K. Blannin, A. M. Clark, L. Cook, P. J. Robson, and M. Gleeson. The effects of high-intensity intermittent exercise on saliva IgA, total protein and a-amylase. J. Sports Sci. 17:129-134, 1999. 
Table 1. Physical characteristics of males $(n=6)$ and females

$(n=5)$. Expressed as mean $\pm \mathrm{SD}$.

\begin{tabular}{|c|c|}
\hline Age (years) & $25.8 \pm 8.1$ \\
\hline Height $(\mathrm{cm})$ & $172.4 \pm 10.4$ \\
\hline Weight $(\mathrm{kg})$ & $73.9 \pm 14.4$ \\
\hline Fat Free Mass (kg) & $62.4 \pm 13.9$ \\
\hline Peak Heart Rate $\left(\mathrm{b} \mathrm{min}{ }^{-1}\right)$ & $188 \pm 6.5$ \\
\hline Heart Rate at VT $(\mathrm{b} \mathrm{min}-1)$ & $149 \pm 22.2$ \\
\hline $\mathrm{VO}_{2 \text { PEAK }}\left(\mathrm{ml} \mathrm{kg}^{-1} \mathrm{~min}\right)$ & $59.5 \pm 11.4$ \\
\hline $\mathrm{VO}_{2 \mathrm{PEAK}}\left(\mathrm{ml} \mathrm{kg} \mathrm{FFM}^{-1} \cdot \mathrm{min}\right)$ & $70.8 \pm 10.1$ \\
\hline $\mathrm{VO}_{2}$ at $\mathrm{VT}\left(\mathrm{ml} \mathrm{kg}^{-1} \mathrm{~min}\right)$ & $35.4 \pm 8.7$ \\
\hline $\mathrm{VT}$ as $\%$ of $\mathrm{VO}_{2 \mathrm{PEAK}}$ & $59.3 \pm 8.8$ \\
\hline
\end{tabular}


Table 2. Actual workload intensities, sweat rate, plasma volume and body weight for the sub-maximal carbohydrate and placebo exercise trials. Expressed as mean \pm SEM.

Placebo

$\mathrm{VO}_{2} *\left(\mathrm{ml} \mathrm{kg}^{-1} \min ^{-1}\right)$

$\% \mathrm{VO}_{2} \mathrm{VT}^{*}$

$\% \mathrm{VO}_{2 \text { PEAK }} *$

RER*

Sweat rate $\left(\mathrm{g} \mathrm{m}^{2(-1)} \mathrm{min}^{-1}\right)$

Plasma Volume (\%)

Change in Body Mass $(\mathrm{kg})$

Change in Body Mass $(\mathrm{kg})^{\dagger}$
$34.8 \pm 2.5$

$98.9 \pm 3.7$

$57.0 \pm 1.2$

$0.86 \pm 0.01$

$22.72 \pm 1.78$

$-1.37 \pm 1.44$

$-0.41 \pm 0.25$

$-1.53 \pm 0.40$
Carbohydrate

$34.4 \pm 2.3$

$97.5 \pm 3.4$

$56.3 \pm 1.2 \%$

$0.89 \pm 0.01$

$22.58 \pm 1.56$

$0.08 \pm 0.42$

$-0.46 \pm 0.29$

$-0.97 \pm 0.37$

*Averages calculated from steady state gas samples collected at 60 and 120 minutes.

${ }^{\dagger}$ Corrected for fluid intake and output between pre and post nude body weights. 
Table 3. Changes in HR, core temperature and RPE during the carbohydrate and placebo exercise trials. Expressed as mean \pm SEM.

\begin{tabular}{|c|c|c|c|c|c|}
\hline Time (min) & 0 & 30 & $\frac{\text { Placebo }}{60}$ & 90 & 120 \\
\hline$H R\left(b \cdot \min ^{-1}\right)$ & $158 \pm 5.6$ & $166 \pm 6.5^{* .+}$ & $171 \pm 5.4^{* .+}$ & $167 \pm 4.8^{*}$ & $172 \pm 4.9^{*}$ \\
\hline Core $\mathrm{T}\left({ }^{\circ} \mathrm{C}\right)$ & $37.28 \pm 0.10$ & $37.86 \pm 0.40^{* . t}$ & $38.60 \pm 0.39^{*}$ & $38.68 \pm 0.41^{*}$ & $38.74 \pm 0.46^{*}$ \\
\hline \multirow[t]{2}{*}{ RPE } & $12.0 \pm 0.65$ & $14.3 \pm 0.40^{*}$ & $15.4 \pm 0.65^{*}$ & $15.4 \pm 0.60^{*}$ & $16.6 \pm 0.62^{*}$ \\
\hline & & & Carbohydrate & & \\
\hline$H R\left(b \min ^{-1}\right)$ & $157 \pm 5.7$ & $167 \pm 5.8^{*}$ & $174 \pm 4.8^{*}$ & $169 \pm 5.4^{*}$ & $170 \pm 5.2^{*}$ \\
\hline Core $\mathrm{T}\left({ }^{\circ} \mathrm{C}\right)$ & $37.34 \pm 0.07$ & $38.34 \pm 0.11^{*}$ & $38.98 \pm 0.17 *$ & $38.89 \pm 0.22^{*}$ & $38.98 \pm 0.26^{*}$ \\
\hline RPE & $12.2 \pm 0.49$ & $14.2 \pm 0.33^{*}$ & $14.8 \pm 0.53^{*}$ & $15.0 \pm 0.60^{*}$ & $15.9 \pm 0.77^{*}$ \\
\hline
\end{tabular}

${ }^{*} \mathrm{p}<0.0346$ (experiment wise alpha $<0.05$ ) vs. rest.

$\uparrow \mathrm{p}<0.0346$ (experiment wise alpha $<0.05$ ) vs. placebo. 
Table 4. Changes in Lactate and Glycerol during the carbohydrate and placebo exercise trials.

\begin{tabular}{l|ccccc|} 
& \multicolumn{5}{c}{ Placebo } \\
& rest & 30 & 60 & 90 & 120 \\
Lactate $(\mathrm{mM})$ & $0.79 \pm 0.10$ & $1.30 \pm 0.24^{*}$ & $1.20 \pm 0.19^{*}$ & $1.08 \pm 0.13^{*}$ & $1.10 \pm 0.11^{*}$ \\
Glycerol $(\mathrm{mM})$ & $0.04 \pm 0.007$ & $0.06 \pm 0.006^{*}$ & $0.06 \pm 0.008^{*}$ & $0.07 \pm 0.006^{*}$ & $0.11 \pm 0.012^{*}$ \\
\hline & \multicolumn{5}{c}{$\frac{\text { Carbohydrate }}{60}$} \\
& rest & 30 & 90 & 120 \\
Lactate $(\mathrm{mM})$ & $0.77 \pm 0.08$ & $1.29 \pm 0.21^{*}$ & $1.03 \pm 0.11^{*}, \dagger$ & $0.93 \pm 0.06^{*}, \dagger$ & $0.96 \pm 0.09^{*}, \dagger$ \\
Glycerol $(\mathrm{mM})$ & $0.04 \pm 0.006$ & $0.06 \pm 0.006^{*}$ & $0.06 \pm 0.009^{*}$ & $0.06 \pm 0.008^{*}$ & $0.10 \pm 1.012^{*}$ \\
\hline
\end{tabular}

*Significant change when compared to rest. $p<0.0346$ (experiment wise alpha $<0.05$ ).

$\dagger$ Significant change when compared to Placebo $p<0.0346$ (experiment wise alpha $<0.05$ ). 
Table 5. Changes in blood immune markers during the carbohydrate and placebo exercise trials. Expressed as mean \pm SEM.

\begin{tabular}{|l|c|c|c|c|}
\multicolumn{1}{c}{} & \multicolumn{2}{c|}{ Placebo } & \multicolumn{2}{c|}{ Carbohydrate } \\
\multicolumn{1}{c}{ time } & Pre & Post & Pre & Post \\
\hline White Blood Cells $\left(1000 \mathrm{~mm}^{3(-1)}\right)$ & $4.95 \pm 0.52$ & $11.69 \pm 0.89^{*}$ & $5.31 \pm 0.35$ & $11.21 \pm 1.54^{*}$ \\
\hline Lymphocytes $\left(1000 \mathrm{~mm}^{3(-1)}\right)$ & $1.63 \pm 0.18$ & $2.79 \pm 0.47^{*}$ & $1.74 \pm 0.24$ & $2.56 \pm 0.62^{*}$ \\
\hline Neutrophils $\left(1000 \mathrm{~mm}^{3(-1)}\right)$ & $2.82 \pm 0.48$ & $7.98 \pm 0.88^{*}$ & $2.96 \pm 0.24$ & $7.78 \pm 1.27^{*}$ \\
\hline Monocytes $\left(1000 \mathrm{~mm}^{3(-1)}\right)$ & $0.40 \pm 0.04$ & $0.77 \pm 0.04^{*}$ & $0.46 \pm 0.03$ & $0.76 \pm 0.11^{*}$ \\
\hline Eosophils $\left(1000 \mathrm{~mm}^{3(-1)}\right)$ & $0.10 \pm 0.02$ & $0.11 \pm 0.02$ & $0.11 \pm 0.03$ & $0.07 \pm 0.02$ \\
\hline
\end{tabular}

All values are corrected for changes in plasma volume.

*Significant change when compared to pre. $\mathrm{p}<0.037$ (experiment wise alpha $<0.05$ ) 


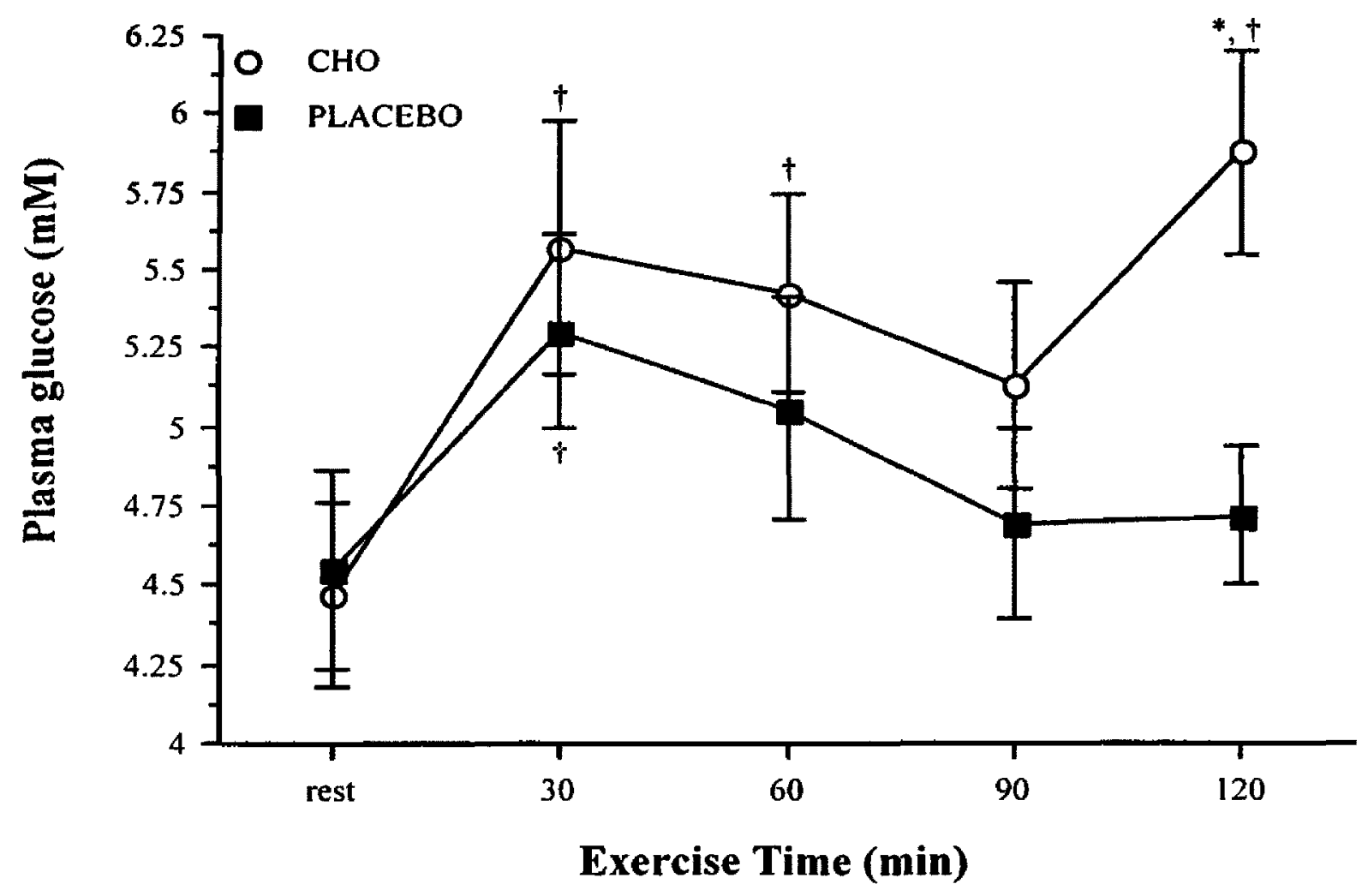




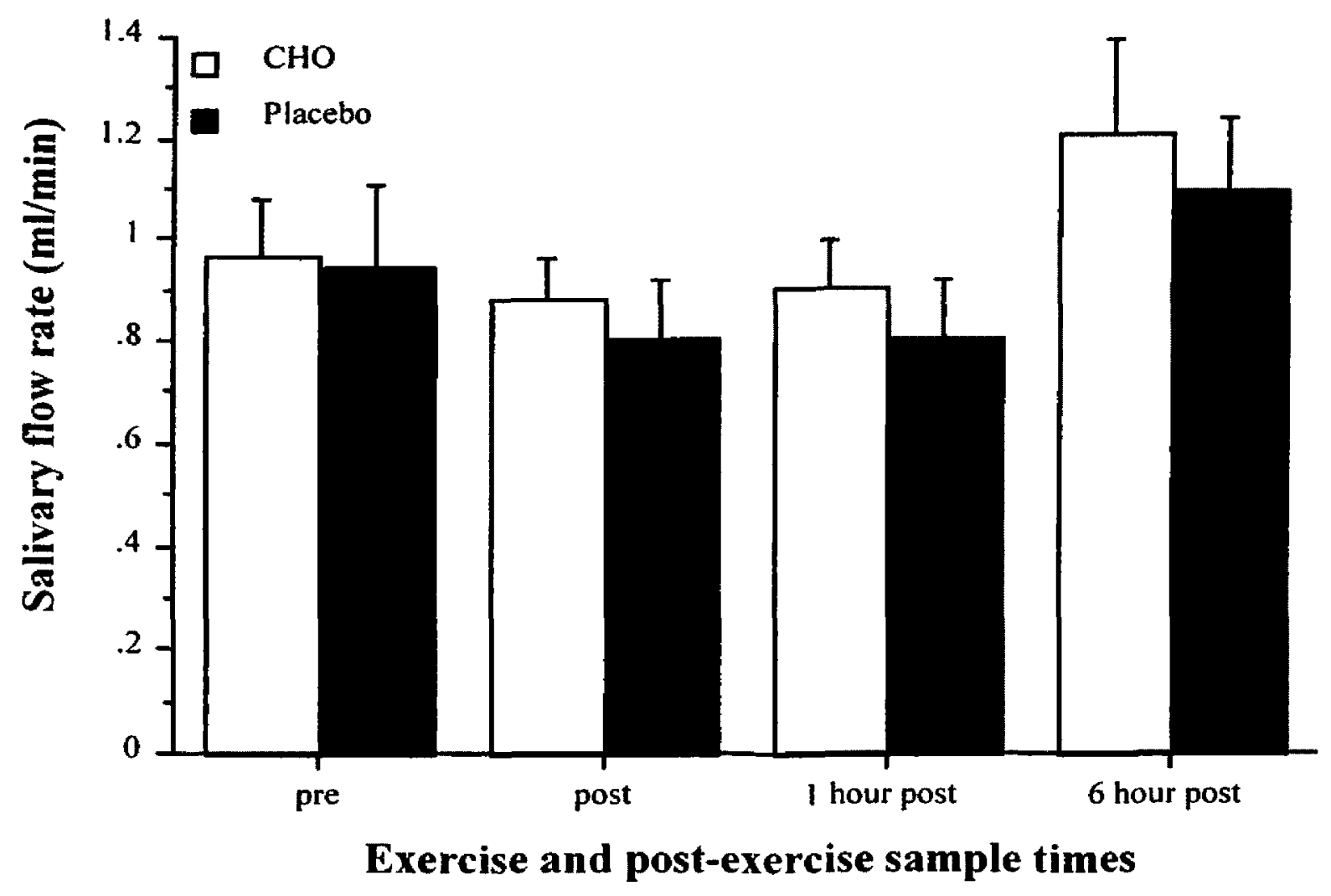




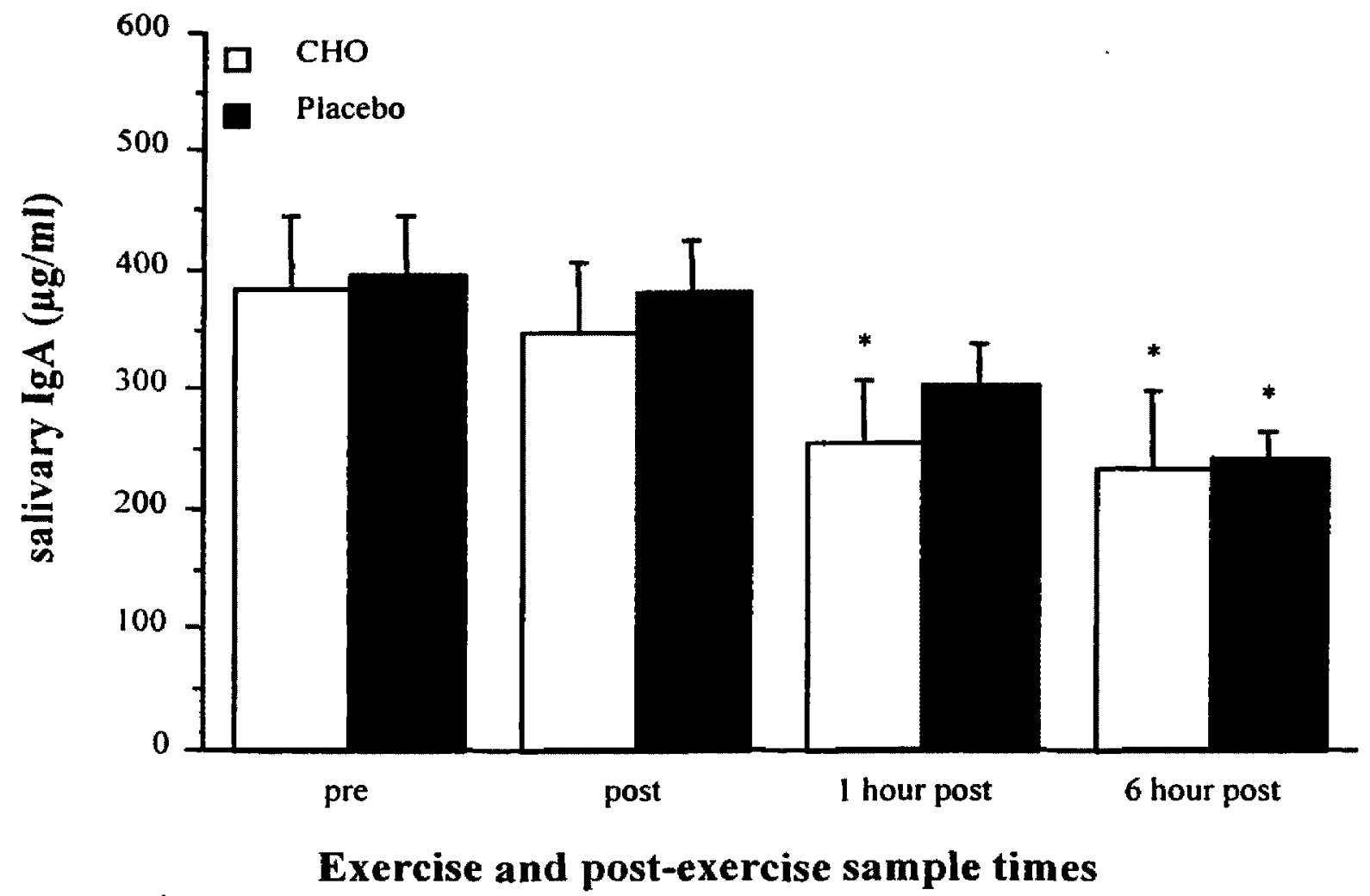




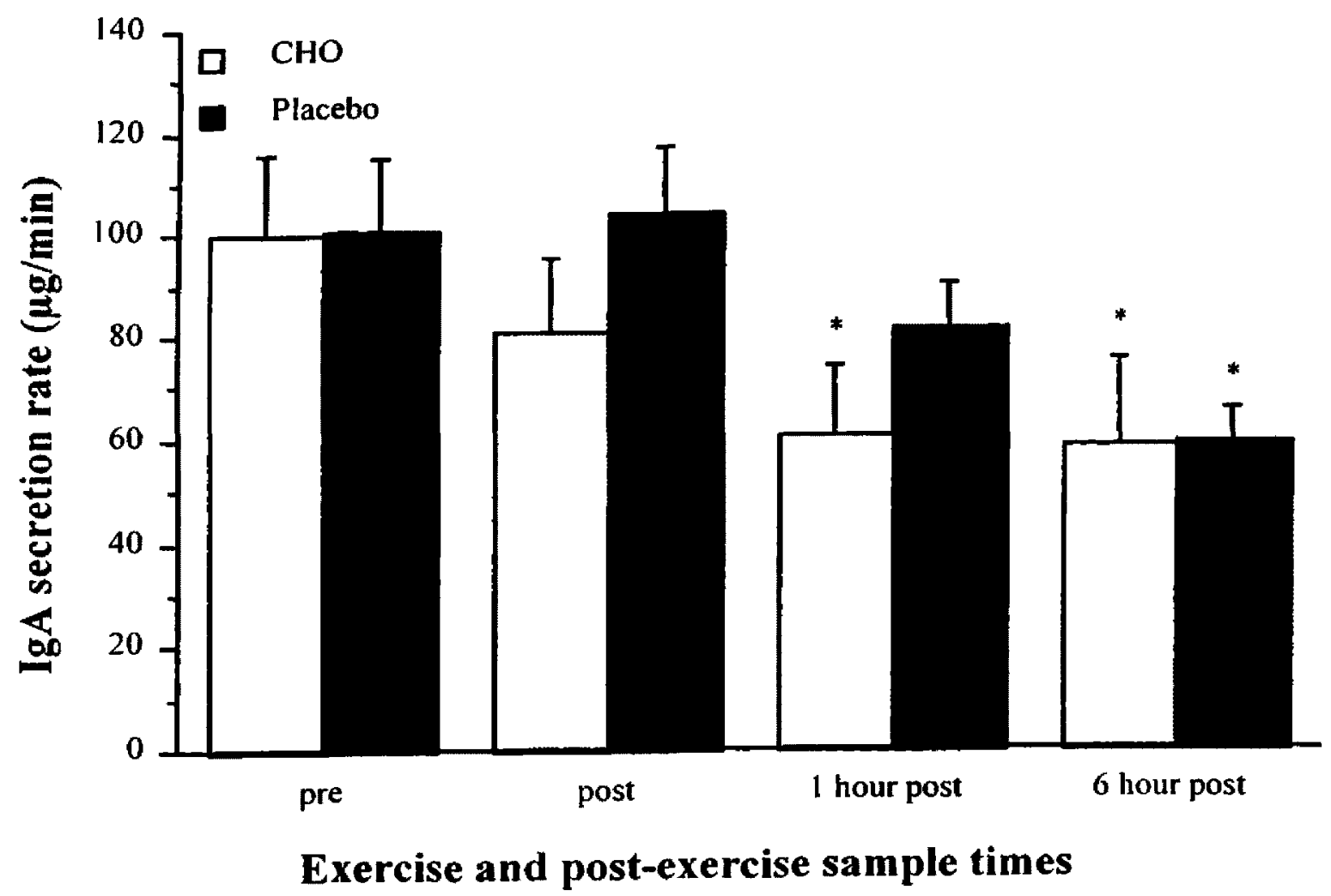




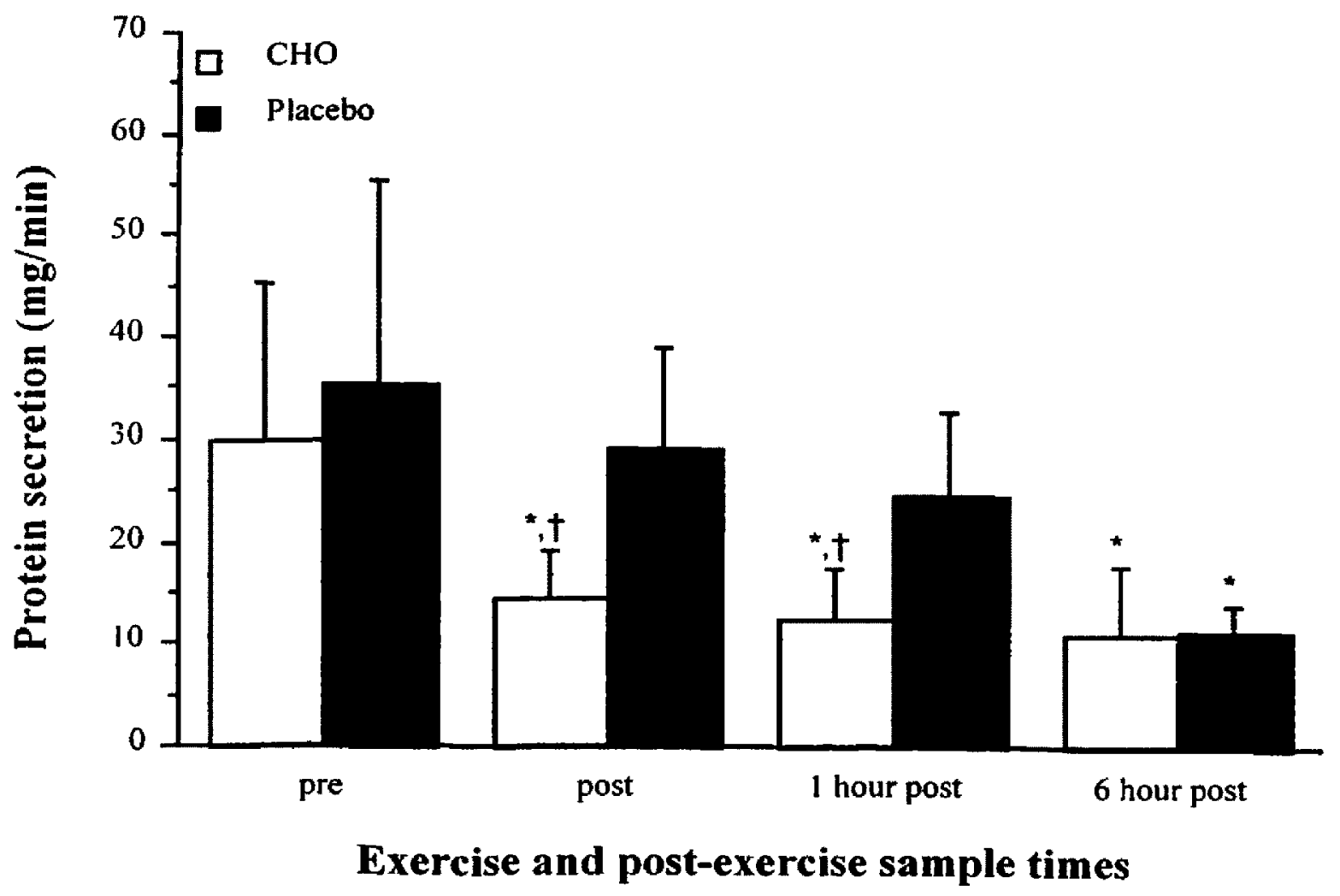




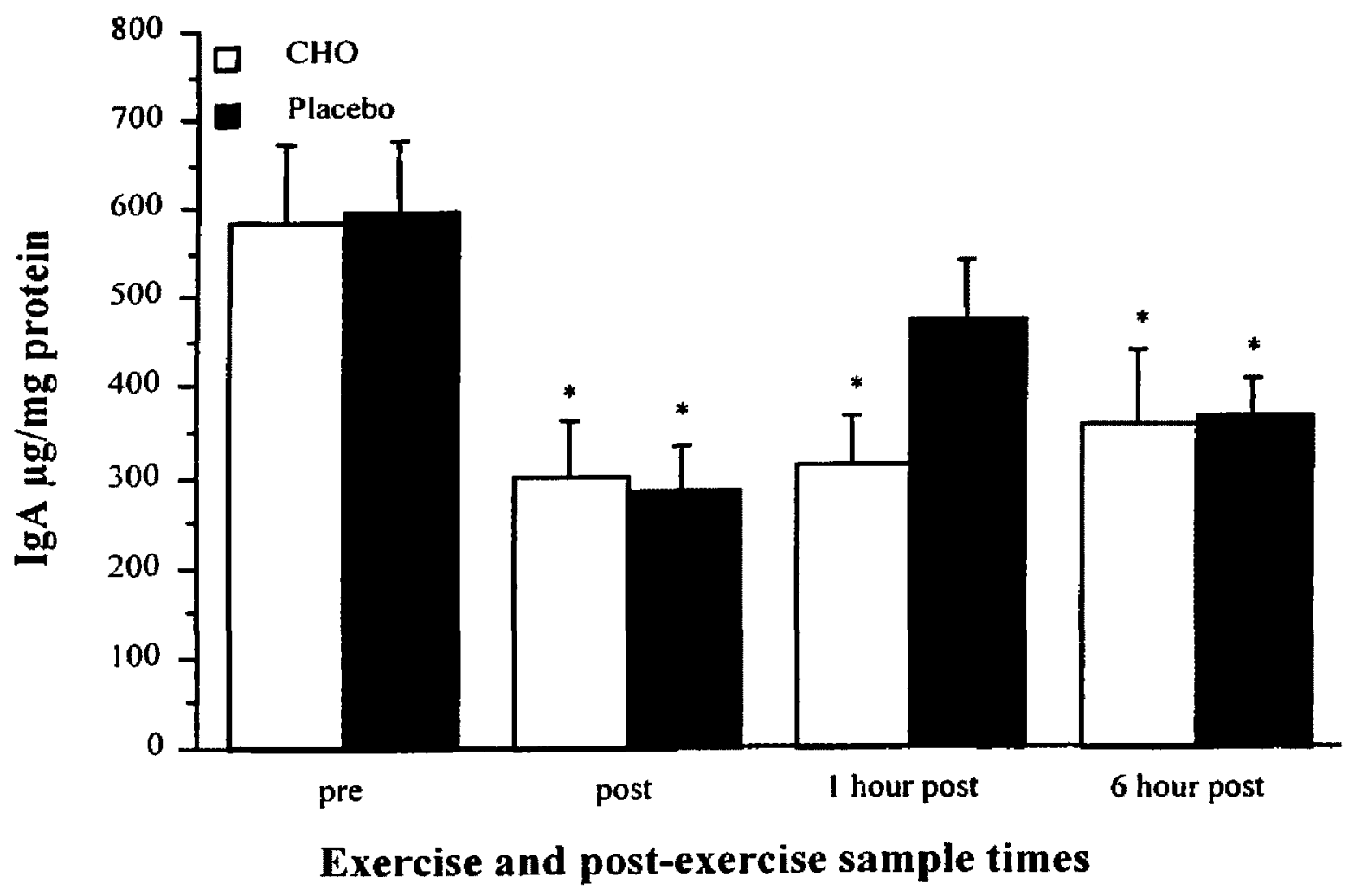


Figure 1. Changes in plasma glucose during the 120 minute exercise trials. * $\mathrm{p}<0.0346$ (experiment wise alpha $<0.05$ ) vs. placebo. $\dagger \mathrm{p}<0.0346$ (experiment wise alpha $<0.05$ ) vs. rest.

Figure 2. Changes in salivary flow rate during the 120 minute exercise trials.

Figure 3. Changes in $\mathrm{s}-\operatorname{IgA}(\mu \mathrm{g} / \mathrm{ml})$ during the 120 minute exercise trials. ${ }^{*} \mathrm{p}<0.035$ (experiment wise alpha $<0.05$ ) vs. rest.

Figure 4. Changes in $\operatorname{IgA}$ secretion rate $(\mu \mathrm{g} / \mathrm{min})$ during the 120 minute exercise trials. ${ }^{*} p<0.035$ (experiment wise alpha $<0.05$ ) vs. rest.

Figure 5. Changes in protein secretion rate during the 120 minute exercise trials. ${ }^{*} \mathrm{p}<0.035$ (experiment wise alpha $<0.05$ ) vs. rest. $\dagger \mathrm{p}<0.0346$ (experiment wise alpha $<0.05$ ) vs. placebo.

Figure 6. Changes in $\mu \mathrm{g} \operatorname{IgA} / \mathrm{mg}$ protein during the 120 minute exercise trials. ${ }^{*} p<0.035$ (experiment wise alpha $<0.05$ ) vs. rest. 